\title{
Using learning analytics to engage students: Improving teaching practices through informed interactions
}

\author{
Justina Naujokaitienè ${ }^{1} \oplus$, Giedrè Tamoliūnè $\dot{1}^{1} \oplus$, Airina Volungevičienè $\dot{e}^{1} \oplus$ and Josep M. Duart ${ }^{2} \oplus$ \\ ${ }^{1}$ Vytautas Magnus University, Lithuania \\ ${ }^{2}$ Universitat Oberta de Catalunya (UOC), Spain
}

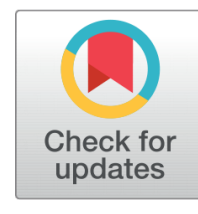

\section{Received 2020-03-16 \\ Revised 2020-04-03 \\ Accepted 2020-05-21 \\ Published 2020-07-15}

Corresponding Author Justina Naujokaitiené, justina.naujokaitiene@vdu.It

Vytautas Magnus University Donelaičio str. 58, Kaunas 44248, Lithuania

DOI https://doi.org/10.7821/

naer.2020.7.561

Pages: 231-244

Funding: European Social Fund (09.3.3-LMT-K-712-01-0189, 09.3.3-LMT-K-712)

Distributed under

Creative Commons CC BY 4.0

Copyright: (C) The Author(s)

\section{ABSTRACT}

Student engagement is one of the most relevant topics within the academic and research community nowadays. Higher education curriculum, teaching and learning integrate new technology- supported learning solutions. New methods and tools enhance teacher and learner interactions and influence learner engagement positively. This research addresses the need to explore new ways of improving teaching practices to better engage students with the help of learning analytics. The paper investigates how university teachers use the data from learning analytics to observe learners and to engage them in online learning. Qualitative inquiry was chosen to approach the research problem, and semi-structured interviews with the teachers using (blended) online learning were conveyed to explore teacher practices in students' behaviour and engagement observations online, disclosing teachers' abilities to understand the challenging learner engagement process based on the data from learning analytics. The new evidence provided by this research highlights the successful practices in the use of learning analytics data to observe students' behaviour and engagement and to inform teachers on the presence needed in order to develop learner-centred activities and to make curriculum changes. The limitation of this study lies in the fact that the different online teaching experiences that research participants had might have restricted their understanding of the use of LA data for curriculum development and learners' engagement.

\section{Keywords STUDENTS' ENGAGEMENT, INFORMATION TECHNOLOGY, ONLINE LEARNING, LEARNING ANALYTICS, TEACHER PRACTICE}

\section{INTRODUCTION}

Active learning through collaborative activities, communication and discussions has come to be important for learners' engagement, the interest, and the overall success of the learning process while teaching and learning online (D. R. Garrison, Anderson, \& Archer, 2000). However, creating the possibilities to communicate and discuss in online learning environments will not ensure the process of collaboration and engagement by itself (Tseng, 2016).

\section{OPEN ACCESS}


Teachers create the pre-conditions for engagement by raising socio-cognitive conflict situations for their learners to discuss or solve them during learning. Often teachers are expected to be more actively involved in the process of discussion and communication taking their role as facilitators (Thorman \& Fidalgo, 2014). Researchers suggest that teachers should observe learners' behaviour in an online learning environment, to analyse the data provided by learning analytics (hereinafter LA), to clarify the need for their more active intervention in facilitating discussions and keeping communication more alive and topic-related (Hew, 2015, 2016; Rienties, Cross, \& Zdráhal, 2017). Such practices may also help teachers to grasp the moments when learners are solving learning situations actively and properly. In that way, the teacher's role could shift from a moderator, a facilitator, to an observer or a collaborator (Herodotou, Rienties, Verdin, \& Boroowa, 2019; Ouyang \& Scharber, 2017), which forces teachers to follow adequate proactive strategies for their interventions (Wong, 2019) by embracing learning in an online environment (Stodel, Thompson, \& MacDonald, 2006).

The responsibilities of teachers in online learning described above reveal the complexity of teachers' roles and the diverse approaches that need to be taken into consideration when discussing learners' engagement in (blended) online learning and suggest how LA can help teachers to better facilitate active learning and collaboration. The Community of Inquiry (COI) framework in online learning, introduced by D. R. Garrison et al. (2000) serves as a model for structuring and recognising dimensions where diverse activities can be organised and developed, ensuring teaching, social and cognitive presence. The choice of learning activities, pacing and grading are key elements of the teaching presence (Anderson, 2017). Feng, Xie and Liu (2017, p. 181) disclose that "different levels of presence should be emphasized at different stages of the course", confirming that teachers should observe learners' behaviour and engagement constantly and change the learning design according to the emerging learner behaviour patterns. The use of LA helps to disclose which activities or tools stimulate learners' engagement (Ma, Han, Yang, \& Cheng, 2015) and so may help to improve social and cognitive presence (Nolan-Grant, 2019). It should be noted that LAdriven research is mostly based on quantitative data analysis which may disclose neither the specific experience of teachers nor the factors that influence learning design, nor teachers' efforts to engage learners into active collaborative learning.

This research aims to answer the question: how do university teachers use the data from Learning Analytics (LA) to observe learners and to engage them in online learning? Therefore, the main focus of this research is to reveal teacher practices in using LA through qualitative research through two perspectives: 1) presenting teacher practices in learner behaviour observations online (qualitative research results from the interviews with teachers); and, 2) disclosing teachers' abilities to understand the challenging learner engagement process based on data from LA.

The new evidence provided by this research highlights the successful practices in the use of LA data to observe learner behaviour and to inform the teacher on the presence needed in order to develop learner-centred activities and to make changes in the course curriculum. In terms of developing learner-centred activities, the research has revealed that LA is helpful 
in facilitating teachers' interventions towards learners' engagement, among them to provoke learners' critical thinking, to induce focused discussions, to stimulate learners' personal interest and original understanding, and to raise learners' awareness of the learning process. From the second perspective about the use of LA information to make changes in the course curriculum, the research highlights benefits such as experimentation with learning activities, making changes and applying new approaches, and making sense of students' reflections on the course tasks.

\section{THEORETICAL BACKGROUND}

The researchers seem to have reached a consensus regarding the fact that educational technologies serve just as a tool through which teaching and learning activities happen. Technologies themselves do not ensure the impact on learning success or achievements, as learning is more affected by the teaching strategy (Ally, 2004).

LA is about learning, enabling the "measurement, collection, analysis and reporting of data about learners and their contexts, for purposes of understanding and optimizing learning and the environments in which it occurs" (Siemens, 2011). Various factors and indicators can be observed with the help of LA data which help teachers to predict learners' performance and recognise behavioural patterns (Anderson, Rourke, Garrison, \& Archer, 2001). Moodle is one of the virtual learning platforms widely used for different educational purposes that provides possibilities for teachers to access the data of learners' behaviour and ensures the analysis of LA data by default functions of the system. It is also compatible with a number of other LA systems that can be integrated with institutional Moodle platforms to provide possibilities for teachers to explore data collected by LA by analysing the visualization and clustering of learner groups' behaviour (Tlili et al., 2019).

Research on LA confirmed that participation and interactions in online learning have a direct impact on learners' success (Ellis, Han, \& Pardo, 2017). Teachers should develop activities which boost learners' critical thinking and engagement, like raising their own questions or reflecting on peers' questions or assignments (Tseng, 2016). Such learning activities would support in-depth learners' engagement, focusing on each one's contribution to discussion forums, providing feedback and raising questions for peers or teachers, seeking and co-constructing knowledge through social interaction and dialogue. However, the concern still remains on whether teachers understand how to read and use LA-driven data to recognize and improve learners' interaction and engagement (Altun \& Kokoc, 2019; van Leeuwen, 2019). The Community of Inquiry (COI) framework is built on teaching, cognitive and social presence (D. Garrison, 2007; D. R. Garrison \& Cleveland-Innes, 2005), that are closely interrelated and interdependent, and focuses on the principles helping to create and sustain the learning community in online learning.

In this study, COI serves as a framework for discussing teacher practices of developing an LA-data-driven learning design, with the focus on teaching and social presence supporting learner engagement in online learning. It is believed that in order to make on-time interventions and changes in the learning process, LA-generated data can serve as a timely indicator 
of emerging aspects of teaching and learning processes, disclosing the implications derived from learning design solutions (Mah, 2016).

Teachers are supposed to enhance learning through opening an online learning environment to access "knowledge $<\ldots>$ distributed across the web, and people's engagement" (Kop, 2011 p. 20) and ensure timely academic support services (Mah \& Ifenthaler, 2019). This implies that teachers should develop new teaching competencies, create engaging online learning and stimulate learners' motivation through different learning activities while designing pedagogical scenarios (Ma et al., 2015). Anderson et al. (2001) state that teaching presence predetermines the student's satisfaction, perceived learning and sense of community.

\section{METHODS}

This study aims to identify the emerging teaching practices of using LA to engage learners into (blended) online learning courses. This study seeks to contribute to the research field of LA by revealing existing practices and disclosing pedagogical LA-data-driven decisions. The qualitative inquiry allowed to disclose how teachers reflect on their practices, perceive their role, make decisions based on LA data and reconsider the learning process by observing students' behaviour.

This study is guided by the research question: how do university teachers use the data from LA to observe learners and to engage them in online learning?

\subsection{Research context}

This study forms part of a wider scope research on the needs of digital and networked society for open and online learning. Research on the use of LA in teaching is implemented in Lithuania and serves as a significant part of the above-mentioned research, by revealing existing practices in higher education, identifying gaps and challenges that detain teachers from developing an LA data-driven learning design.

The research presented in this study discusses the institutional case of a university in Lithuania where all courses are available in Moodle. The increasing number of Moodle courses delivered in a blended or online mode reveals the emerging importance of teachers' awareness of the potential of LA, especially when it is related to the improvement of learning design focusing on learners' engagement. Moreover, it helps to disclose what kind of support teachers need to succeed in this process. This is extremely important for teachers who transform their traditional classes into blended or online ones. Moreover, the research results serve as constructive suggestions for higher education institutions and may serve as a guiding tool for the development of teachers' professional development activities.

\subsection{Research participants}

The research participants were selected on the basis of their initial interest and agreement to participate in the research. Aiming to ensure the variety of teachers from different fields of study who had different teaching online experiences, and to respond to ethical data pro- 
tection issues regarding their course content, a two-stage process was applied to identify the interviewees. Firstly, a short questionnaire was uploaded onto the institutional Moodle platform asking teachers to express their availability and willingness to share their experiences regarding the usage of Moodle tools to observe learners' behaviour in their courses. In addition to asking about teachers' awareness to use Moodle tools to observe learners' behaviour and the usefulness of these tools, teachers were invited to participate in the follow-up interviews to share their experience in greater detail. Out of 145 teachers who responded to this short survey, 130 teachers were aware of the possibility to extract data on learners' behavior, 88 of them were using some of those tools, 73 of 88 found them useful, and 36 of the respondents agreed to participate in the follow-up interview. In the follow-up stage, researchers contacted teachers personally by emails and invited them to give interviews. 25 teachers out of 36 agreed to participate and share their experiences in greater depth. The two-phase process for identifying research participants helped not only to ensure a variety of experiences and interviewees' willingness to share their teaching practices but also to guarantee research validity.

A qualitative approach was used to collect 25 interviews with university teachers who delivered (blended) online learning courses in Moodle. Research participants covered 10 study fields: economics, natural sciences, education, agriculture, philology, law, mathematics, computer science, communication and psychology. The age of interviewees varied between 29 and 63, with the online teaching experience varying from 2 to 15 years.

\subsection{Data collection and management}

Semi-structured interviews were used to collect data, following the set of topics as interview guidelines. After research participants provided their consent to participate in this research, a date, time and place were arranged with each interviewee individually. Before the interview, research participants were reminded of the research aim, introduced with the ethical procedures to ensure the confidentiality of their identities. The average length of interview was 50 minutes. Interviews were audio-taped and transcribed right after the interview. Each interviewee was appointed with a code (I1, I2, I3...I25).

\subsection{Data analysis}

Qualitative content analysis was chosen to analyse interviews and to present research findings. The analysis was led by the research question, enabling researchers to construct a set of categories that are "sufficiently precise to enable different coders to arrive at the same results when the same body of material is examined" (Silverman, 2007, p. 159). To ensure the validity of data analysis, two researchers examined the interviews and coded segments of texts individually. Following the procedures of qualitative data analysis, interviews were re-read multiple times, the main segments of texts were coded, codes were reviewed and grouped together into subcategories and categories. At the final stage, researchers discussed and mutually agreed on the final categories, ensuring their conformity with the interview extracts. This process allowed to ensure the replicability of findings, when common shared understanding was achieved by multiple researchers. 


\section{RESULTS}

As mentioned above, data analysis was driven by the research question: how do university teachers use LA to engage learners in (blended) online learning courses? The research question was analysed and answered from a dual perspective which is represented by two overarching categories: developing learner-centred activities; and changing the course curriculum depending on LA data. Sub-categories were constructed to disclose the complexity of each category.

The analyses of interviews disclosed that all research participants were aware of the possibility to access data provided by LA. Nevertheless, their awareness of how this data could be used to improve blended or online courses appeared to be rather limited. The results revealed that in most cases, teachers observe and analyse frequencies of students' log-ins and the assignment submission deadlines: "I see all the time, that if there are eighty students, then there are around twenty of them who always stay behind $<\ldots>$ and this number even increases when the assignment deadline approaches" (I17). Despite being rather disappointed to see the low level of engagement into the course, the research participants believe that seeing how some of the students are constantly engaged into course motivates to continue the development of (an) engaging learning.

It discloses another significant aspect of LA data for teaching practices -the possibility to observe learners' (dis)engagement with the course and its material, which may be a motivating factor for the development of a more interactive course, or, on the contrary, a prevailing feeling that discourages the development of an interactive and engaging course. The research participants emphasized that LA data provided a unique possibility to see if the learner got acquainted with a course plan and student handbook that is seen as an important initial step for the engagement into the course. As long as the course plan and the student handbook included all the relevant information about the course, the possibility to see which students read the documents decreased the responsibility of the teacher in regard to the timely information of course assignments or approaching deadlines: " $<\ldots$.. from the follow-up activities I can see who has read, and who has not even opened and looked at it [the student handbook]" (I22). This demonstrates that it takes some time for teachers to and rethink what data is related to the learning success or progress and how.

\subsection{Developing learner-centred activities}

As the analysis of interviews disclosed, teachers put their efforts to create a learning environment that promotes a more active learners' engagement and makes them develop their critical thinking. Next to developing diverse forms of tasks and learning activities, in a total of 25 interviewees, 16 included additional forms of external motivators factors helping to engage students into deeper learning: " $<\ldots>$ there is a forum next to each topic where they should share daily experiences about the phenomenon that they study that week. $<\ldots>$ And if they share $<\ldots>$ they receive a badge at the end of the semester" (I18).

The research participants believe that in such a way, students are encouraged to demonstrate their critical thinking capacity, relate their knowledge to the existing events, reflect on them and get more actively involved in discussions. And while the prior example demon- 
strates how teachers foster students' engagement with the course content after the topic is discussed in the classroom, other research participants believe that discussing the topic in advance may stimulate learners' interest and allows them to construct their own knowledge: "I explain that next time we will analyse one or the other topic, ask $\langle\ldots\rangle$ to observe if anything is happening $\langle\ldots\rangle$ related to that topic, and present those observations at the beginning of the next class" (I02). Teachers' decisions are based on the aim to shift the responsibility for the learning process to the learners themselves. Teachers aim to foster learners to reflect on their personal experiences and knowledge, and in such a way, to prepare for the discussions of an upcoming class topic. This confirms teachers' understanding that critical thinking scaffolds the learning process and provokes the emergence of a wide range of students' thinking skills -“...it demonstrates $<\ldots .>$ if students bring any ideas to the class, if they are brave enough to present them, to share them with a friend..." (I02). Sharing ideas with other learners fosters their sense of belonging to the group and induces the social presence of the community.

As can be seen, teachers are keen to provoke internal motivators factors using different tasks which allow students to demonstrate their critical thinking skills and explain the subject matter in an everyday context. In a total of 25 interviewees, 8 have developed noncompulsory assignments in their courses for learners to do, aiming to stimulate their cognitive and social presence development, especially of those who prefer self-regulated learning and demonstrate a more active engagement into the learning process.

Encouraging learners to construct their own knowledge through collaborative activities is another important aspect of emergent teaching practices. Next to the above-mentioned intentions of stimulating learners' personal interest and original understanding, other research participants believe that collaborative activities in which students are encouraged to ask, negotiate and communicate with colleagues, stimulate their social presence significantly. At the same time, scaffolding these kinds of activities contributes to the teaching presence, especially when the learning content is developed in collaboration with students: "We use 'Wiki' to create a common document $\langle\ldots\rangle$ We choose the topic and then each student adds separate words to the vocabulary" (I25). Furthermore, other teachers involve students in the creation of a task which is included in the course as a part of another assignment: " $<\ldots>$ quite often students create questions during the class, I then upload those questions onto the 'database', and then use those questions either to solve in class, or at home" (I02). As can be seen, the success of students' engagement depends a lot on the teacher's willingness to develop multiple activities and tasks promoting learners' critical thinking, sense of belonging and personal interest. Co-creation of learning content empowers students to be more engaged to the course.

When talking about the specific tools allowing the observation of learners' progress and engagement, research participants emphasised the importance of the data provided by means of a progress bar. The analysis and usage of the data provided by the progress bar is treated as a great tool which raises learners' awareness of their learning process. To achieve best results, only 7 of 25 interviewees emphasize how important it is to develop the blended or online course that is coherent and where all activities are purposeful and 
competence-oriented: " $<\ldots>$ I relate each assignment to the competences $<\ldots$. they can see which competence they had in mind to make the assignment and the extent to which they succeeded" (I24).

The analysis of interviews confirms that teachers' practices in students' observations online and their abilities to understand the challenging learners' engagement based on the data provided by LA needs to be reconsidered from multiple perspectives. The data shows that teachers are creative enough in creating engaging tasks or encouraging learners' contribution to the development of course content. Multiple tools are used and activities developed. Through the use of different learning methods and observations of students' input into the learning process, it is possible to disclose the teaching presence in online courses, which appeared to be intertwined with the social and cognitive presence. Overall, it becomes evident that teachers are provoking students' cognitive and social development processes through the teaching presence, by raising their awareness on the learning process itself.

\subsection{Changing the course curriculum}

Interview data analysis proved the importance of discussing how teachers use LA data to observe learners' engagement and performance in the course from two perspectives: first, from teachers' willingness to develop and create learner-centred activities; and, second, to implement timely changes in course curriculum in response to LA data.

Experimentation with learning activities reveals teaching presence. It is important for teachers to analyse the reasons and think metacognitively about the risk of learning failures. In most cases, analysis and reflection appear only after students fail to deliver a task. In such a case, teachers need to rethink whether it was a problem of task difficulty, students' unpreparedness or an insufficient explanation of the task: "[i]f I see that most of the students failed to implement the task in a way that I expected them to do it, I understand that my material was not clear enough or maybe was presented in a wrong format" (I01). Teachers' self-reflection and self-criticism prompts a more active rethinking of the changes that should be made. They try to prevent failures by, for example, discussing the task earlier and giving the opportunity for students to focus on the given task in advance: "I encouraged them to start thinking about the homework earlier, $\langle\ldots\rangle$ it helps me not to get lost, as I put them into some frameworks from the beginning to ensure that their homework is all at the same quality level" (I01). Data analysis demonstrates that curriculum designing is not a static process; instead, it should be seen as going through continuous changes related to the improvement and design of learning activities or tasks. Research participants confirm that next to grades, LA data helps them to grasp challenging moments related to students' task implementation or engagement and to make changes to curriculum which are possible at that learning phase.

Moreover, the research participants demonstrate different practices and experiences related to making changes and applying new approaches towards the development of learning activities. While some teachers share the tendency to stick to the curriculum that is set up and to revise content or exercises only each semester, others make timely changes related 
to the improvement of activities: "if I feel that $\langle\ldots\rangle$ tasks are too difficult, $<\ldots>$ that there's a significant delay $\langle\ldots\rangle$, I make changes, either by shifting individual activities into group work, or by simply ignoring them" (I22).

All research participants shared a unanimous understanding that having the possibility to observe learners' activities and engagement provided them with important directions on what changes are needed in teaching and learning. In most cases, when the tasks were not working well with the students, teachers tended to change tasks only next year, when new students join the course. This kind of decision may not seem very reasonable when thinking that all groups of students are different and so, if the task does not work well with one group, it might be a success with another. Thus, the next question worth posing in this research is: what evidence do teachers need to make changes in learning design?

The research revealed that student reflections are invited during teaching and learning to suggest how learning and curriculum could be improved. Therefore, making sense of students' reflections on the course tasks emerged as an important factor demonstrating the need for teachers' reflection and curriculum re-designing.

Students' reflection on the learning process is one of the major factors helping teachers to measure the success of the course and learners' engagement. Students' metacognitive thinking allows them to make sense of their learning, and provides interesting information for teachers about the cognitive and teaching presence: " $<\ldots$. $>$ when I ask students to upload the assignment, I ask them to make comments, just to initiate the metacognitive process, how which they succeeded with the task, if it was significant" (I23).

The research results demonstrate that changes in the curriculum are made on time aiming to respond to learners' needs and that they are based on students' reflections and observations. Even though not each type of data is provided by LA directly, learners' feedback and provision of critical comments demonstrate learners' engagement and interest in the course content. Having the possibility to access learners' feedback and observe their participation in the course, as well as their engagement with the content, helps teachers to react to the emerging challenges rather quickly, which is very important for students' success. In this case, teachers' practices in using LA for course development encompass the social, cognitive and teaching presences.

\section{DISCUSSION}

The analysis of interviews with higher education teachers on their experience using LA data to improve (blended) online learning revealed that teachers share rather similar approaches towards the researched question. A difference exists between the way teachers think that (blended) online learning should be designed and how they design it. Teachers often seem to be "attached" to teaching and learning activities that they have used for years in physical learning and teaching environments. However, they agree that what was working quite well in physical settings does not work well online. They raise considerations on how learning should be redesigned, focusing on learners' behaviour and their engagement into learning. 
This research confirmed that teachers focus a lot on the development and inducement of social networking and on building a sense of belonging. Nevertheless, as claimed by Tseng (2016), the process and success of collaboration requires much more than just the creation of a space for engagement. Teachers tended to choose discussion forums hoping that this might increase learners' interest in the topic, even awarding additional points for an active participation in discussions. Student engagement is even assessed introducing it as an evaluation criterion, counting and observing students' answers or questions raised. However, as shown by data analysis, teaching presence is much more important than social or cognitive presence to ensure learners' engagement.

LA provides teachers with data that helps them to improve learning design. Teachers observe and analyse the data which is easiest to access: frequencies of students' log-ins and deadlines for assignment submissions. How is this linked and sufficient for learning design efficiency and improvement indicators? Nolan-Grant (2019) confirms that LA can supply much more data, helping to approach cognitive and social presence. The teaching presence was revealed in research when teachers discussed the selection of different active learning methods used in their course, the presentation of learning resources and the formulation of different tasks. The results support the research undertaken by Anderson (2017), explaining teaching presence through the choice of curriculum design, learning activities, pacing and grading. Ma et al. (2015) emphasize the importance of different types of motivators factors, and this research shows that looking from the teacher's perspective, students respond to the motivation system in most cases, as well, but not in all cases, and sometimes teachers' decisions or their chosen strategies did not succeed, as students did not express any deeper interest in the developed activities. When evidence shows that only a minority of students engage in learning activities, the question is why is the task, or an external motivator factor, not replaced in the course?

Teaching presence is important to facilitate students' cognitive presence also by shifting the responsibility of learning process to students themselves. Vitoulis (2017) claims that learning is the process built to stimulate each person's reflections. To achieve that, teachers ask learners to observe their everyday experiences, which might be consistent with the subject they teach and explain the theory in practice by bringing the teaching and learning experience to a higher cognitive level. In such a way, the approach to learning as 'content and knowledge' is shifted to learning as co-production of knowledge. Furthermore, the task which prompts students to reflect might be related to the social presence as an important factor in the way of learning.

Through the use of different learning methods and observations of students' input into the learning process, it is possible to disclose the teaching presence in online learning, which appeared to be intertwined with social and cognitive presence. Unfortunately, not all reasons why and how teachers use LA to improve learning were observed. Further research would be needed for a closer look at the reasons and the speed of teachers' decisions and the changes they make in learning design based on LA. 


\section{CONCLUSIONS}

This research was focused on the question: how do university teachers use LA to engage learners in (blended) online learning courses? This study confirmed that university teachers, despite being aware of the possibility to access LA data and use it for curriculum designing and learners' engagement, have a very limited understanding of how this data could help them to make changes in curriculum design. Teachers use LA aiming to see what happens in the course, to what extent students get involved in tasks and how they collaborate during learning. Teachers try to predict and make changes on the basis of LA information. It appeared that, in some cases, changes are made on-time, reacting to the emerging situation, while sometimes, teachers choose to make changes only the next semester, when the course is delivered to another group of students.

The analysis of the research data from the interviews revealed that teachers take into consideration LA data to observe learner's behaviour in virtual learning environments. They are able to consider the data and act upon this data when they develop learner-centred activities and make changes in the course curriculum.

In terms of developing learner-centred activities, the research revealed that the use of LA to facilitate learner engagement is helpful to make teacher interventions to provoke learner critical thinking easier, to induce focused discussions, to stimulate learners' personal interest and original understanding, and to raise learners' awareness of the learning process.

From the second perspective about the use of LA-data-driven information to make changes in the course curriculum, the research highlights benefits such as experimentation with learning activities, making changes and applying new approaches, and making sense of students' reflections on course tasks.

Overall, teachers demonstrate very basic practices of learning analytics data in their daily practice. The LA data they observe and analyse is not used to predict learners' behaviour in the course; rather, data help them to see if the tasks are explained in a clear and sufficient way, if learners' are aware of the course curriculum and if they deliver assignments on time. The only prediction that was observed in relation to students' engagement was the presumption that, if students get acknowledged with the student handbook, it is more likely that they will be more aware of the overall learning process and become more actively engaged. It is important to emphasize that a need exists to invest on teacher competence development in the use of LA to enhance students' engagement.

This study has some potential limitations. The fact that the research participants had different online teaching experiences might have restricted the understanding of the use of LA data for curriculum development and learners' engagement. The interviews were collected in Lithuanian, and consequently, translations into English might have incorporated minor adaptations of the experiences expressed. Despite the limitations mentioned, this study discloses the need for further in-depth research on teacher practices aiming to analyse how decisions are made based on specific problems, and how the tools and online teaching methods help to ensure and stimulate social presence. This leads to the idea that a longitudinal study could provide a more detailed picture of how course curriculum is planned, revised and changed based on LA data, considering social, teaching and cognitive presences. 


\section{ACKNOWLEDGEMENTS}

Funded by: Europan Social Fund, EUE

Funder Identifier: http://dx.doi.org/10.13039/501100004895

Awards: 09.3.3-LMT-K-712-01-0189; 09.3.3-LMT-K-712

The research has been implemented within the framework of the research project "Open and Online Learning for Digitalised and Networked Society" (project No. 09.3.3-LMT-K712-01-0189) funded by the European Social Fund according to the activity "Improvement of researchers' qualification by implementing world-class R\&D projects" of Measure No. 09.3.3-LMT-K-712.

\section{REFERENCES}

Ally, M. (2004). Foundations of educational theory for online learning. In A. Terry (Ed.), Theory and Practice of Online Learning (pp. 15-44). Edmonton: Athabasca University Press.

Altun, A., \& Kokoc, M. (2019). Following the learners' traces: Profiling learners and visualizing the learning process for building better learning experiences. In M. S. Khine (Ed.), Emerging Trends in Learning Analytics: Leveraging the Power of Education Data (pp. 100-121). Brill. https://doi.org/10.1163/9789004399273_007

Anderson, T. (2017, 02 01). How communities of inquiry drive teaching and learning in the digital age. [Blog post]. Retrieved from https://teachonline.ca/sites/default/files/pdf/e-newsletters/ how_communities_of_inquiry_drive_teaching_and_learning_in_the_digital.pdf

Anderson, T., Rourke, L., Garrison, R., \& Archer, W. (2001). Assessing teaching presence in a computer conferencing context. Online Learning, 5, 1-17. https://doi.org/10.24059/olj.v5i2 .1875

Ellis, R. A., Han, F., \& Pardo, A. (2017). Improving learning analytics - combining observational and self-report data on student learning. Journal of Educational Technology \& Society, 20(3), $158-169$.

Feng, X., Xie, J., \& Liu, Y. (2017). Using the community of inquiry framework to scaffold online tutoring. The International Review of Research in Open and Distributed Learning, 18(2), 162188. https://doi.org/10.19173/irrodl.v18i2.2362

Garrison, D. (2007). Online community of inquiry review: Social, cognitive, and teaching presence issues. Journal of Asynchronous Learning Networks, 11(1), 61-72. https://doi.org/10.24059/ olj.v11i1.1737

Garrison, D. R., Anderson, T., \& Archer, W. (2000). Critical inquiry in a text-based environment: Computer conferencing in higher education. The Internet and Higher education, 2(2), 16-22. https://doi.org/10.1016/S1096-7516(00)00016-6

Garrison, D. R., \& Cleveland-Innes, M. (2005). Facilitating Cognitive Presence in Online Learning: Interaction Is Not Enough. American Journal of Distance Education, 19(3), 133-148. https:// doi.org/10.1207/s15389286ajde1903_2

Herodotou, C., Rienties, B., Verdin, B., \& Boroowa, A. (2019). Predictive Learning Analytics "At Scale": Towards Guidelines to Successful Implementation in Higher Education Based on the Case of the Open University UK. Journal of Learning Analytics, 6(1), 85-95. https://doi.org/ 10.18608/jla.2019.61.5

Hew, K. F. (2015). Student perceptions of peers versus instructor facilitation of asynchronous online discussions: Further finding from three cases. Instructional Science, 43(1), 19-38. https:// doi.org/10.1007/s11251-014-9329-2 
Hew, K. F. (2016). Promoting engagement in online courses: What strategies can we learn from three highly rated MOOCs? British Journal of Educational Technology, 47(2), 320-341. https:// doi.org/10.1111/bjet.12235

Kop, R. (2011). The challenges to connectivist learning on open online networks: Learning experiences during a massive open online course. The International Review of Research in Open and Distributed Learning, 12(3), 19-19. https://doi.org/10.19173/irrodl.v12i3.882

Ma, J., Han, X., Yang, J., \& Cheng, J. (2015). Examining the necessary condition for engagement in an online learning environment based on learning analytics approach: The role of the instructor. Internet and Higher education, 24, 26-34. https://doi.org/10.1016/j.iheduc.2014.09.005

Mah, D. K. (2016). Learning analytics and digital badges: Potential impact on student retention in higher education. Technology, Knowledge and Learning, 21(3), 285-305. https://doi.org/ 10.1007/s10758-016-9286-8

Mah, D.-K., \& Ifenthaler, D. (2019). What do first-year students need? Digital badges for academic support to enhance student retention. Journal of Applied Research in Higher Education, 12(1), 86-96. https://doi.org/10.1108/jarhe-12-2018-0258

Nolan-Grant, C. R. (2019). The Community of Inquiry framework as learning design model: a case study in postgraduate online education. Research in Learning Technology, 27(0), 27-27. https://doi.org/10.25304/rlt.v27.2240

Ouyang, F., \& Scharber, C. (2017). The influences of an experienced instructor's discussion design and facilitation on an online learning community development: A social network analysis study. The Internet and Higher Education, 35, 34-47. https://doi.org/10.1016/j.iheduc.2017.07 .002

Rienties, B., Cross, S., \& Zdráhal, Z. (2017). Implementing a Learning Analytics intervention and evaluation framework: What works? In B. K. Daniel \& R. Butson (Eds.), Big Data and Learning Analytics in Higher Education: Current Theory and Practice (pp. 147-166). Springer. https:// doi.org/10.1007/978-3-319-06520-5_10

Siemens, G. (2011). Learning analytics \& Knowledge. 1st International Conference on Learning Analytics and Knowledge. Retrieved from https://tekri.athabascau.ca/analytics/

Silverman, D. (2007). Interpreting Qualitative Data: Methods for Analysing Talk, Text and Interaction (3rd ed.). London: Sage.

Stodel, E. J., Thompson, T. L., \& MacDonald, C. J. (2006). Learners' Perspectives on what is Missing from Online Learning: Interpretations through the Community of Inquiry Framework. The International Review of Research in Open and Distributed Learning, 7(3). https://doi.org/10 .19173/irrodl.v7i3.325

Thorman, J., \& Fidalgo, P. (2014). Guidelines for online course moderation and community building from a student's perspective. Journal of Online Learning and Teaching, 10(3), 374-388.

Tlili, A., Denden, M., Essalmi, F., Jemni, M., Chang, M., \& Chen, N.-S. (2019). Automatic modeling learner's personality using learning analytics approach in an intelligent Moodle learning platform. Interactive Learning Environments, 1-15. https://doi.org/10.1080/10494820.2019 .1636084

Tseng, S. (2016). Who will pass? Analyzing learner behaviors in MOOCs. Research and Practice in Technology Enhanced Learning, 11(8). https://doi.org/10.1186/s41039-016-0033-5

van Leeuwen, A. (2019). Teachers' perceptions of the usability of learning analytics reports in a flipped university course: when and how does information become actionable knowledge? Educational Technology Research and Development, 67(5), 1043-1064. https://doi.org/ 10.1007/s11423-018-09639-y

Vitoulis, M. (2017). Prospects of connectivism in lifelong professional training of early childhood educator in the framework of digital pedagogy-perceptions, attitudes and intentions. 
European Journal of Social Sciences Studies, 2(7), 1-22. Retrieved from https://oapub.org/soc/ index.php/EJSSS/article/view/156/457

Wong, J. (2019). Educational theories and learning analytics: From data to knowledge. In E. D. Ifenthaler, D. Mah, \& J. Yau (Eds.), Utilizing Learning Analytics to Support Study Success (pp. 3-25). Springer. https://doi.org/10.1007/978-3-319-64792-0_1 